\title{
A Study of the Behavioural Factors Associated with Low Uptake of Intra-Uterine Contraceptive Device in Zaria, Northern Nigeria: A Qualitative Survey
}

\author{
Abdul Muhammad Adogie 1*, Halima Abdul Musa², Nana Hauwa Madugu1, Ummi Bawa1 \\ ${ }^{1}$ Reproductive Health and General Gynecology Unit, Department of Obstetrics and Gynecology Ahmadu Bello \\ University Teaching Hospital, Zaria, Nigeria \\ ${ }^{2}$ Department of Nursing Sciences, Ahmadu Bello University, Zaria, Nigeria \\ Email: :maabdul90@gmail.com
}

Received 11 September 2015; accepted 5 December 2015; published 8 December 2015

Copyright @ 2015 by authors and Scientific Research Publishing Inc.

This work is licensed under the Creative Commons Attribution International License (CC BY).

http://creativecommons.org/licenses/by/4.0/

c) (i) Open Access

\begin{abstract}
Aim: To document reasons for the low uptake of Copper 380A contraceptive in Zaria, Northern Nigeria. Study Design: Qualitative analysis from In-depth interviews (IDI) and Focus group discussions (FGD). Setting: Zaria, Northern Nigeria. Methods: Five high volume public facilities within Zaria metropolis were selected for the study (the teaching hospital, two district hospitals serving the metropolis and two primary care centers). The most experienced provider in each of these facilities was engaged in an IDI to explore reasons for the low uptake of IUD from their perspective. Similarly, a session of FGD was conducted in each of the facility involving at least eight family planning clients who were para 4 or more and not using the IUD. Results: There were a total of 397 new clients that were served various methods of contraceptive across the five facilities three months prior to the study. Intrauterine device only accounted for $11.8 \%$ of these clients while Injectable was responsible for $62 \%$ of clients. $72 \%$ of the IUD insertions took place in the teaching hospital. There were no IUD insertions in the two primary care centers within the last three months prior to study. Conclusion: Misconceptions, lack of information concerning IUD particularly at the primary care levels, lack of male involvement and providers' incompetence were the main barriers to accessing IUD services in Zaria, Nigeria. In the course of this investigation, local Ethics were observed.
\end{abstract}

${ }^{*}$ Corresponding author. 
Keywords

Contraceptive, IUD, Clients, Providers, Misconceptions, Uptake, Facility

\section{Introduction}

Current data revealed that the contraceptive prevalence rate of Nigeria is about $10 \%$ and this is far less than the African average of 30\% [1] [2]. Like maternal mortality ratio, Nigerian contraceptive prevalence is associated with a wide regional variation with higher prevalence in southern compared with the northern parts of the country [3]. Established data also documented regional differences in the pattern of contraceptive use. In the South-West and South-South, Intrauterine device (IUD) is the commonest contraceptive in use accounting for $30 \%-55 \%$ of clients [4]-[6]. In the South-East, injectable contraceptive and fertility awareness methods are the commonest methods in use [7] [8]. In North-West and North East the injectables appeared to be the commonest method accounting for over $50 \%$ of clients [9] [10], whereas in the North-Central region over one-third of clients used the IUD [11].

Copper-T IUD is perhaps the most effective reversible modern contraceptive. It is very cheap (compare to hormonal implants), highly effective, have fewer side effects, not client dependent with a robust eligibility criteria. Despite these advantages, it was observed that IUD uptake is very low in many urban and rural parts of Northern Nigeria [10]. The same situation has been documented in some parts of Africa [12]-[14]. Of all the reversible modern contraceptives, the Copper IUD is perhaps the most surrounded with myths and misconceptions particularly in sub-Saharan Africa. These misconceptions are not only from the clients but also from family planning providers [14].

There are very few studies that explored the reasons for the low uptake of IUD in our setting and nearly all these studies utilized quantitative methods with their attendant limitations. In this submission, we investigated the factors militating against the uptake of IUD from both the provider and client perspective using qualitative methods. It is hoped that findings from this study will provide information for appropriate interventions to improve the uptake of IUD in the country's quest of improving the contraceptive prevalence rate and by extension accelerate its attainment of meeting the goals of MDG5. However, this survey was not extended to the relationship between cost of contraceptive and end users financial status.

\section{Materials and Methods}

This study was a qualitative investigation with a minor quantitative component. Five high volume public health facilities within Zaria metropolis were selected for the study using multistage sampling technique. First, the public health facilities within Zaria (North Western Nigeria) metropolis were stratified into tertiary, secondary and primary levels of care. The only tertiary care center-Ahmadu Bello University Teaching Hospital (ABUTH) and the two general (district) hospitals within the metropolis were selected to represent the tertiary and secondary levels of care respectively. Two of the 15 primary care centers within Zaria metropolis were selected for the study based on the volume of FP clients. In each of the selected facilities, the most experience provider was engaged in an In-depth Interview (IDI) session to explore reasons for the low uptake of IUD and strategies for improvement. Similarly, a session of Focus Group Discussion (FGD) was conducted in each of the selected facility involving at least six family planning clients who were para 4 or more and not using the IUD. The main themes of the FGD include routine information on IUD, reasons for not choosing IUD and the possibility of using IUD in future. The FGD was largely conducted in the local language-Hausa. The quantitative part of the study involved the scrutinization of service delivery records of family planning services three months prior to survey, in each of the selected facilities.

The data of the IDIs and FGDs were transcribed and analyzed manually. Data from the service delivery record was also manually analyzed using thematic content analysis approach.

\section{Results and Discussion}

\subsection{Results}

The service delivery records revealed that there were a total of 397 clients served with various modern contra- 
ceptives across the five selected facilities of which IUD accounted for only $12 \%$ of the methods while injectable contraceptives were given to $62 \%$ of the clients (Table 1). Of the 47 IUD (CU-T 380A) insertions that occurred during the period under review, $34 \%$ or $72 \%$ were inserted in the Teaching Hospital while the remaining 13 were inserted in one of the secondary level facility. No client was served with IUD in any of the two primary care centers. In the primary health care centers, only injectable and combined oral contraceptives were served or documented, with injectable accounting for $84 \%$ of the clients.

\subsubsection{Findings from IDI}

All the five providers interviewed were trained and have been offering FP services for at least five years. Only two providers (in the Teaching Hospital and HGSMH) had inserted IUD within 10 days prior to the interview while others had not inserted IUD for over six months before the IDI. When asked to cite reasons, the two providers in the PHCs stated lack of instruments/commodity, IUD insertion increases work load, lack of demand and not very confident to provide IUD services. One of the PHC based provider confessed as follows "Honestly IUD has a lot of complications particularly PID which will cause infertility; isn't it? I don't like it and will not allow any of my sisters to use it'. The other provider in the other secondary care facility simply cited lack of demand for it even though they do not routinely provide information concerning IUD.

On exploration of the reasons for the general low uptake of IUD in Zaria, the teaching hospital provider painted a picture as thus "some few years back, IUD uptake is very low in this facility but with increasing provision of contraceptive information and more importantly with provision of good quality service that meets client's satisfaction who spread the news to their friends/relatives, IUD is now competing favorably with hormonal contraceptives. In this part of the country, women take information from friends more seriously than from health workers. IUD is surrounded with lots of misconceptions even among us the providers. Clients believe IUD can migrate to the brain, causes infection and cancer and interferes with sexual performance/pleasure; I have encountered few clients that complained about their husband complaining of some pricking sensation on their genitals and so want their IUD removed". Other providers apart from upholding above submission particularly in the aspect of coital interference added that clients perceived IUD insertion to be painful and involved the provider "scrutinizing their genitals even through the provider is a female". Another sexual dimension of IUD was stated by the provider in one of the district hospital as follows "some clients believe that IUD reduces sexual pleasure and this give their husband an excuse to deprive them of not only sex but other needs and instead pay more attention to his other wife/wives." Only one of the providers (in PHC) mentioned cost to be an inhibitory factor in IUD uptake.

\subsubsection{Findings from FGDs}

Of the five FGDs sessions, the sessions in the primary care centers were the most engaging. The data is presented under the following themes-

1) Routine information on IUD from the facilities:

While all the clients in the tertiary center admitted receiving some information on IUD and other contraceptives from the providers, the same was not obtainable in the lower levels of care. Only three out of seven of the clients that participated in the FGD in one of secondary care center said they receive counseling of FP including

Table 1. Distribution of FP methods across the selected facilities three months prior to survey (April-June 2012).

\begin{tabular}{ccccc}
\hline Health Facility & No of clients for IUD & $\begin{array}{c}\text { No of clients for } \\
\text { Injectable }\end{array}$ & $\begin{array}{c}\text { No of clients for other } \\
\text { methods }\end{array}$ & Total clients \\
\hline ABUTH Zaria & 34 & 32 & 58 & 124 \\
HGSMH & 13 & 42 & 15 & 3 \\
MAMH & - & 25 & 3 & 28 \\
PHC Tudun Wada Zaria & - & 95 & 25 & 98 \\
PHC Baban Dodo Zaria & - & 52 & $104(26.2 \%)$ & 397 \\
\hline
\end{tabular}

HGSMH-Hajiya Gambo Sawaba Memorial Hospital; MAMH- Major Abdullahi Memorial Hospital. 
IUD, virtually all other clients in the other three facilities submitted not receiving any information on IUD from the providers. Their knowledge on IUD was largely from friends/relatives.

2) Procedure for insertion and complications of IUD:

Some clients perceived the procedure of IUD insertion too complex, painful and associated with lots of complications which include infection, cancer and infertility. One of the clients in one of the primary care centers put it this way “I don't like the insertion process of IUD—one will open wide her private parts, then there is insertion of some iron instruments-no wonder we heard that it can damage the womb and subsequently cause difficulty to conceive". One other client added that "we heard IUD can migrate to other parts of the body. It can even migrate to the brain and cause damage. We heard stories of babies born with IUD in their hands-this is certainly making one secret open and a bad testimony. And you want us to use this contraception? Never". Yet another client in one of the secondary care center added that "Because the insertion of IUD is not simple and may be associated with problems, our husband permission is needed and most of our husbands are not in support of contraception".

3) Sexual performance and related issues

Majority of the clients in the secondary care and PHC facilities believe that IUD interferes with sexual performance (reduce pleasure), causes dyspareunia, and genital tract infection. One of the clients submitted thus "my friend told me that when she used IUD after her last child birth, her husband no longer enjoyed her sexually and keep complaining of some pricking sensation during coitus. He paid more attention to her mate. She had to remove it and settled for injectable."

4) Other findings

Few of the clients expressed fear of the unknown and will attribute any illness they will suffer to it. One client, again in one of the PHC was rather philosophical/religious by stating "The womb is a sacred place-it is only meant for babies and nothing else. If I die with the IUD in my womb, what will I tell Almighty God?"

\subsection{Discussion}

The findings from the quantitative data (Table 1) are consistent with the previous reports from the region. The commonest method is injectable responsible for nearly two-thirds of the clients. This is similar to the reports by Aliyu et al. from Zaria [15] and Abdul and co-workers [10] from the North-Eastern part of Nigeria. Furthermore IUD merely accounted for $12 \%$ of all methods and nearly two-third of the insertions were in the tertiary care facility. It should be noted that no single IUD was inserted in any of the selected PHCs during the period of the survey and these PHCs has the largest volume of antenatal (at least 150 new clients per week) and FP clients within Zaria metropolis. This finding certainly has implication for FP programming. To improve the uptake of long term contraceptives (including IUD) at the grassroots, PHCs must be targeted. Our figure of $12 \%$ for IUD prevalence is lower than previous report from Zaria by Ameh and colleagues [9] of 22\%. This may be accounted for by the differences in the study methods. While Ameh's data were restricted to the teaching hospital, our data was more robust by including secondary and primary care facilities. The IUD prevalence rate in this study is similar to the 7\% prevalence rate reported by Ogbonna and co-workers [16] in a community survey in Jos-North LGA in Plateau State in North-central Nigeria. However Mutihir and colleagues [11] in the same LGA but in a tertiary care center, reported an IUD prevalence rate of $26 \%$.

The findings from IDIs were very revealing-provider bias and lack of competence for provision of IUD services particularly at the lower level of care were readily palpable and these may be responsible for the lack of demand creation by the provision of routine information on IUD. These findings are similar to that found among providers in South Africa [13] [17] and Kenya [14]. It should be noted that cost did not appear to be a factor militating against IUD uptake.

The revelations from the clients were most interesting. The submission by majority of clients in this study that the source of information on IUD was from friends/relatives is consistent with established data in Nigeria [2] [15] [16] [18]. Clients' perception of IUD association with cancer of the womb, infection and damage to the womb with resultant infertility is not uncommon myths attributable to IUD among women in Africa [12]-[14] [19] [20]. Similar finding was documented among women in Scotland [21]. Association of IUD with reduce sexual pleasure and dyspareunia by the clients further stresses the magnitude of the myths/misconceptions surrounding the IUD and this underscores the importance of provision of accurate FP information by competent providers using multiple media. Considering the uterus a "sacred place" made only for nurturing fetuses may probably be con- 
sidered a philosophical/religious dimension to the misconceptions surrounding the IUD by African women. Involvement of religious/traditional/opinion leaders in family planning programs may be helpful in dispelling some of the myths/misconceptions surrounding contraception generally. The importance of this intervention cannot be overemphasized in traditional Northern Nigerian communities.

It can be concluded that IUD uptake is indeed low in our setting particularly at the lower levels of health care. Misconceptions, lack of information concerning IUD, lack of male involvement and providers' incompetence were the main barriers to accessing IUD services in Zaria. Investments in training/retraining of providers, involvement of men including local traditional/religious leaders and information dissemination including IEC materials and sustainable commodity management may be cost effective mechanisms to improve the uptake of IUD services in our setting. However, this survey was not extended to the relationship between cost of contraceptive and end users financial status.

\section{Acknowledgements}

The authors are grateful to the management of Hajiya Gambo Sawaba and Major Abdullahi Memorial Hospitals and the Head of Health of Zaria Local Government Council for using their health facilities for the study. In the course of this investigation local Ethics was observed.

\section{Conflict of Interest}

The authors have no conflicts of interest.

\section{References}

[1] National Population Commission. NDHS 2008. National Population Commission. ORC Marco, Calverton.

[2] Oye-Adeniran, B.A., Adewale, I.F., Umoh, A.V., Oladokun, A. and Gbadegesin, A. (2005) Sources of Contraceptive Commodity for Users in Nigeria. PLoS Medicine, 2, e306. http://dx.doi.org/10.1371/journal.pmed.0020306

[3] Mandara, M. (2012) Family Planning in Nigeria and Prospects for the Future. International Journal of Gynecology \& Obstetrics, 117, 1-4. http://dx.doi.org/10.1016/j.ijgo.2012.01.002

[4] Adegbola, O. and Ogedengbe, O.K. (2008) The Acceptance Rate of Intrauterine Contraceptive Device (IUCD) amongst Family Planning Clinic Users in Lagos University Teaching Hospital (LUTH). Nigerian Quarterly Journal of Hospital Medicine, 18, 175-180.

[5] Adeyemi, A.S., Adekanle, D.A. and Komolafe, J.O. (2008) Pattern of Contraceptives Choice among the Married Women Attending the Family Planning Clinic of a Tertiary Health Institution. Nigerian Quarterly Journal of Hospital Medicine, 17, 67-70. http://dx.doi.org/10.4314/njm.v17i1.37359

[6] Abasiattai, A.M., Bassey, E.A. and Udoma, E.J. (2008) Profile of Intrauterine Contraceptive Device Acceptors at the University of Uyo Teaching Hospital, Uyo, Nigeria. Annals of African Medicine, 7, 1-5. http://dx.doi.org/10.4103/1596-3519.55692

[7] Chigbu, B., Onwere, S., Aluka, C., Kamanu, C., Okoro, O. and Feyi-Waboso, P. (2010) Contraceptive Choices of Women in Rural Southeastern Nigeria. Nigerian Journal of Clinical Practice, 13, 195-199.

[8] Ugboaja, J., Nwosu, B.O., Ifeadike, C.O., Nnebue, C.C. and Obi-Nwosu, A.I. (2011) Contraceptive Choices and Practices among Urban Woman in Southeastern Nigeria. Nigerian Journal of Medicine, 20, 360-365.

[9] Ameh, N. and Sule, S.T. (2007) Contraceptive Choices among Women in Zaria, Nigeria. Nigerian Journal of Clinical Practice, 10, 205-207.

[10] Abdul, M.A., Shittu, S.O., Madugu, N.H., Adaji, S.E. and Aliyu, A.A. (2012) Situation Analysis of Family Planning Services at the Secondary Level of Care in Three Least Underserved Northern Nigerian States: Implications for the Attainment of Millennium Development Goal. International Journal of Gynecology Obstetrics, 119, 409-410. http://dx.doi.org/10.1016/S0020-7292(12)60850-9

[11] Mutihir, J.T. and Pam, V.C. (2008) Overview of Contraceptive Use in Jos University Teaching Hospital, North Central Nigeria. Nigerian Journal of Clinical Practice, 11, 139-143.

[12] Neukom, J., Chilambwe, J., Mkandawire, J., Mbewe, R.K. and Hubacher, D. (2011) Dedicated Providers of Long-Acting Reversible Contraception: New Approach in Zambia. Contraception, 83, 447-452. http://dx.doi.org/10.1016/j.contraception.2010.08.021

[13] VanZijl, S., Morroni, C. and van der Spuy, Z.M. (2010) A Survey to Assess Knowledge and Acceptability of the Intrauterine Device in the Family Planning Services in Cape Town, South Africa. Journal of Family Planning and Repro- 
ductive Health Care, 36, 73-78. http://dx.doi.org/10.1783/147118910791069367

[14] Wesson, J., Olawo, A., Bukusi, V., Solomon, M., Pierre-Louis, B., Stanback, J. and Janowitz, B. (2008) Reaching Providers Is Not Enough to Increase IUD Use: A Factorial Experiment of “Academic Detailing” in Kenya. Journal of Biosocial Science, 40, 69-82. http://dx.doi.org/10.1017/S0021932007002027

[15] Madugu, N.H., Abdul, M.A., Bawa, U. and Kolawole, B. (2015) Uptake of Hormonal Implants Contraceptive in Zaria, Northern Nigeria. Open Journal of Obstetrics and Gynecology, 5, 268-273. http://dx.doi.org/10.4236/ojog.2015.55039

[16] Ogbonna, C. and Pam, I.C. (2006) A Cross-Sectional Study on Contraceptive Use among Married Women in Jos, Plateau State. Nigerian Medical Practitioner, 50, 107-109.

[17] Gutin, S.A., Mlobeli, R., Moss, M., Buga, G. and Morroni, C. (2011) Survey of Knowledge, Attitudes and Practices Surrounding the Intrauterine Device in South Africa. Contraception, 83, 145-150. http://dx.doi.org/10.1016/j.contraception.2010.07.009

[18] Oye-Adeniran, B.A., Adewale, I.F., Odeyemi, K.A., Ekanem, E.E. and Umoh, A.V. (2005) Contraceptive Prevalence among Young Women in Nigeria. Journal of Obstetrics and Gynaecology, 25, 182-185. http://dx.doi.org/10.1080/01443610500041156

[19] Nwachukwu, I. and Obasi, O.O. (2008) Use of Modern Birth Control Methods among Rural Communities in Imo State, Nigeria. African Journal of Reproductive Health, 12, 101-108.

[20] Adegbola, O. and Okunowo, A. (2009) Intended Postpartum Contraceptive Use among Pregnant and Puerperal Women at a University Teaching Hospital. Archives of Gynecology and Obstetrics, 280, 987-992. http://dx.doi.org/10.1007/s00404-009-1056-6

[21] Glasier, A., Scorer, J. and Bigrigg, A. (2008) Attitudes of Women in Scotland to Contraception: A Qualitative Study to Explore the Acceptability of Long-Acting Methods. Journal of Family Planning and Reproductive Health Care, 34, 213-217. http://dx.doi.org/10.1783/147118908786000497 